\title{
Despertar da comunicação científica no Ensino Médio integrado à Educação
}

\section{Profissional}

\author{
Awakening of scientific communication in High School integrated with Professional Education \\ Despertar de la comunicación científica en el bachillerato integrado con la Formación Profesional
}

Recebido: 08/11/2021 | Revisado: 20/11/2021 | Aceito: 08/12/2021 | Publicado: 17/12/2021

Thiago de Lima Silva

ORCID: https://orcid.org/0000-0003-0152-4060 Instituto Federal da Paraíba, Brasil

E-mail: thiagobibliotecario@gmail.com

Diogo Pereira Bezerra

ORCID: https://orcid.org/0000-0002-0159-4117 Instituto Federal do Rio Grande do Norte, Brasil E-mail: diogo.bezerra@ifrn.edu.br

\begin{abstract}
Resumo
Comunicação científica aliada ao conhecimento é de suma importância para desenvolvimento da sociedade contemporânea e consequentemente um ato libertador a partir do momento em que é gerida como um valor estratégico determinante e um bem que deve ser compartilhado. Este estudo teve como objetivo investigar como os alunos do primeiro ano do ensino médio integrado à Educação Profissional e Tecnológica (EPT) através das ferramentas de comunicação científica tende a se comportar quanto ao domínio e apropriação dessas ferramentas onde foi realizada uma oficina com a pretensão de desenvolver habilidades básicas sobre diversas formas de acessar a comunicação científica através das bases de dados, formalizar esse conhecimento através do preenchimento/atualização do currículo Lattes e conhecer de que forma se dá a estruturação do projeto de pesquisa através da ABNT NBR 15287:2011. A coleta de dados foi feita através de análise de conteúdo de Bardin e aplicação de questionário para que pudéssemos observar a evolução e o progresso das atividades durante a oficina. Dentre as propostas da oficina verificou que as temáticas abordadas para esse público específico foram tidas como inéditas visto que a sua grande maioria tinha pouco ou nenhum conhecimento dos assuntos sendo na aplicação da oficina o primeiro contato com as temáticas da comunicação científica. Através da coleta de dados tivemos como compreender que quando a comunicação científica é incentivada ainda na adolescência, esses jovens tem o poder de entender, interpretar e criar um senso crítico através de fontes confiáveis gerando a partir desse tripé (entender, interpretar e criticar).
\end{abstract}

Palavras-chave: Comunicação científica; Educação profissional; Ensino médio integrado.

\begin{abstract}
Scientific communication coupled with knowledge is of paramount importance for the development of contemporary society and consequently a liberating act from the moment it is managed as a determining strategic value and a good that must be shared. This study aimed to investigate how students in the first year of high school integrated with Vocational and Technological Education (EFA) through scientific communication tools tend to behave in terms of mastery and appropriation of these tools where a workshop was held with the intention to develop basic skills on various ways of accessing scientific communication through databases, formalize this knowledge by completing / updating the Lattes curriculum and knowing how the research project is structured through ABNT NBR 15287: 2011. Data collection was carried out by analyzing Bardin's content and applying a questionnaire so that we could observe the evolution and progress of activities during the workshop. Among the workshop's proposals, it was found that the themes addressed to this specific audience were considered to be unprecedented since the vast majority had little or no knowledge of the subjects, with the workshop being the first contact with the themes of scientific communication. Through data collection we were able to understand that when scientific communication is encouraged even in adolescence, these young people have the power to understand, interpret and create a critical sense through reliable sources generating from this tripod (understand, interpret and criticize) others possible themes building and contributing to a more appropriate and qualified knowledge for society.
\end{abstract}

Keywords: Scientific communication; Vocational education; Integrated high school.

\section{Resumen}

La comunicación científica combinada con el conocimiento es de suma importancia para el desarrollo de la sociedad contemporánea y, en consecuencia, un acto liberador desde el momento en que se gestiona como un valor estratégico determinante y un bien que debe ser compartido. El presente estudio tuvo como objetivo investigar cómo los estudiantes de primer año de bachillerato integrados a la Educación Profesional y Tecnológica (EPT) a través de 
herramientas de comunicación científica tienden a comportarse en términos de dominio y apropiación de estas herramientas, donde se realizó un taller con la intención de desarrollar conocimientos básicos. habilidades sobre diferentes formas de acceder a la comunicación científica a través de bases de datos, formalizar este conocimiento llenando / actualizando el currículum de Lattes y conociendo cómo se lleva a cabo la estructuración del proyecto de investigación a través de ABNT NBR 15287: 2011. La recolección de datos se realizó mediante el análisis de contenido de Bardin y la aplicación de cuestionarios para que pudiéramos observar la evolución y avance de las actividades durante el taller. Entre las propuestas del taller, se verificó que los temas dirigidos a este público específico se vieron como nuevos, ya que la gran mayoría tenía poco o ningún conocimiento de los temas, y la aplicación del taller fue el primer contacto con los temas de la comunicación científica. . A través de la recolección de datos, pudimos entender que cuando se fomenta la comunicación científica aún en la adolescencia, estos jóvenes tienen el poder de comprender, interpretar y generar sentido crítico a través de fuentes confiables, generando desde este trípode (comprender, interpretar y criticar) otras posibles temáticas construyendo y contribuyendo a un conocimiento más adecuado y cualificado para la sociedad.

Palabras clave: Comunicación científica; Educación profesional; Bachillerato integrado.

\section{Introdução}

A palavra "comunicar" tem como significado, segundo Holanda (2000), ato ou efeito de emissão, transmissão e recebimento de mensagens através de métodos e/ou processos que são ajustados, que pode ser através da fala ou da escrita, ou até mesmo por demais sinais, signos ou símbolos fazendo com que os seres humanos possam compreender os fatos que estão ao seu redor, de acordo com o seu nível de construção de pensamento, porém os comunica de forma diferenciado devido ao momento de evolução que se encontra. Sabendo-se que os indivíduos passam por situações de aprendizagem que se diferenciam através do contato com algum tipo de leitura e com seu nível de interação com o objeto de conhecimento que é, em nossa pesquisa, o uso da comunicação científica (Francisco \& Fernandes-Sobrinho, 2020; Barbosa \& Moreira, 2020; Junior et al., 2021).

A comunicação científica é considerada pelos educadores um desafio, pois embora inseridos em um ambiente repleto de informações, muitas vezes pode ser relevante o distanciamento entre indivíduos e essas formas de comunicação devido a fatores como a inexistência de acesso ou até mesmo de incentivo dessas pessoas pela percepção dos recursos que estão à sua volta. A comunicação científica quando aliada ao conhecimento se torna um ato libertador a partir do momento em que a mesma tem um valor estratégico determinante e um bem que deve ser disseminado.

Segundo Demo (2003, p. 7), “a aula que apenas transfere conhecimento, ou a instituição de ensino que somente se delimita como socializadora do conhecimento, não sai do ponto de partida, e, na prática não ajuda o aluno, porque o deixa como objeto de ensino e instrução".

Nesse contexto, a instituição de ensino deve estar preparada para contribuir para a formação de pessoas com condições para desempenhar em uma sociedade cada vez mais diversificada e assumindo que a educação pela pesquisa pode ser um estímulo para a ascensão, no sujeito, aprendizados que possibilitem o "desenvolvimento da autonomia intelectual, da consciência crítica" (Demo, 2003, p. 86), com a capacidade de indagar e de expressar criticamente na sua realidade.

Neste sentido, percebemos que as bibliotecas (físicas ou virtuais) podem oferecer uma excelente utilidade para as instituições de ensino, no desenvolvimento das competências informacionais, onde temos a percepção de que a informação é deve ser compreendida como uma fonte de conhecimentos, habilidades e atitudes para alcançar um determinado resultado (Cunha, 1997; Morigi \& Pavan, 2004; Olinto, 2010; Ribeiro \& Chahini, 2021). Deve ser estimulada nos usuários das bibliotecas, para que os mesmos possam cada vez mais ter a sua autonomia intelectual para desenvolver com êxito o trabalho com informação e produzir conhecimento (Ninsembau, 2001).

O presente estudo pretendeu investigar como os alunos do primeiro ano do ensino médio integrado à educação profissional e tecnológica através das ferramentas de comunicação científica tende a se comportar quanto ao domínio e a apropriação dessas ferramentas onde foi realizado uma oficina com o intuito de desenvolver habilidades básicas sobre diversas 
formas de acessar a comunicação científica através de uma pesquisa-ação onde segundo Thiollent (2007, p. 15) esse tipo de pesquisa permite que o investigador exerça "um papel ativo no equacionamento dos problemas, no acompanhamento e na avaliação das ações desencadeadas em função dos problemas", caracterizando pelo desencadeamento de ações e reflexões acerca das ações realizadas (Barbier, 2007; Saraiva \& dos Anjos, 2020; Baldino, 2021). A comunicação científica quando estimulada ainda no ensino médio integrado à educação profissional e tecnológica poderá formar cidadãos com entendimento, interpretação e senso mais crítico baseado em fonte confiáveis de informação (Magalhães et al., 2021).

\section{Metodologia}

O presente estudo pretendeu investigar como os alunos do primeiro ano do ensino médio integrado à educação profissional e tecnológica através das ferramentas de comunicação científica tende a se comportar quanto ao domínio e a apropriação dessas ferramentas onde foi realizado uma oficina com o intuito de desenvolver habilidades básicas sobre diversas formas de acessar a comunicação científica através de uma pesquisa-ação onde segundo Thiollent (2007, p. 15) esse tipo de pesquisa permite que o investigador exerça "um papel ativo no equacionamento dos problemas, no acompanhamento e na avaliação das ações desencadeadas em função dos problemas", caracterizando pelo desencadeamento de ações e reflexões acerca das ações realizadas. A comunicação científica quando estimulada ainda no ensino médio integrado à educação profissional e tecnológica poderá formar cidadãos com entendimento, interpretação e senso mais crítico baseado em fonte confiáveis de informação.

\subsection{Oficina Pedagógica}

Assim sendo foi realizado uma oficina com os alunos do primeiro ano do ensino médio integrado com a finalidade de contribuir para o despertar da comunicação científica desde o primeiro ano do ensino médio integrado incentivando a pesquisa como princípio educativo. A inscrição foi feita em duas etapas onde a primeira foi através da ferramenta Formulários do Google onde se inscreveram 33 alunos dos cursos de Contabilidade, Meio Ambiente, Mecânica e Edificações. Nessa primeira etapa foi explicado que a oficina seria de forma remota em que o aluno inscrito teria que ter acesso a computador ou equipamento que pudesse ter acesso ao Google Meet e Google Sala de Aula com acesso à internet. Ainda nessa primeira etapa foi estabelecido que as datas dos encontros seriam nos dias 1, 8, 15 e 22 de dezembro de 2020. Foi perguntado também qual seria o melhor horário para a realização da oficina, sendo fornecido três opções: $09 \mathrm{~h}, 15 \mathrm{~h}$ ou $17 \mathrm{~h}$. A segunda etapa consistiu em encaminhar por e-mail para os inscritos o Termo de Consentimento Livre e Esclarecido (TCLE), o Termo de Assentimento Livre e Esclarecido (TALE) e o termo de gravação de áudio. Nessa etapa tivemos o retorno de 21 alunos dos cursos de Contabilidade, Mecânica e Edificações. A validação da inscrição na oficina ficou condicionada a entrega dos termos assinados. Quanto as questões éticas dessa pesquisa foram ressaltadas que os participantes poderiam a qualquer momento se desligar da pesquisa e que o anonimato seria preservado.

A oficina foi desenvolvida em quatro semanas com uma carga horária total de 12 horas. O link de acesso ao Google Meet e Google Sala de Aula foram enviados para os participantes com 24 horas de antecedência.

Os materiais das quatro semanas ficaram disponibilizados através do Google Sala de Aula e os encontros da oficina no Google Meet onde houve a exposição dos temas propostos na oficina. Já no primeiro encontro houve a sugestão de se formar um grupo no WhatsApp entre os participantes com objetivo de se formar um grupo de estudo entre eles.

A oficina "O despertar da comunicação científica", direcionado aos alunos do primeiro ano do ensino médio integrado, aconteceu semanalmente no mês de dezembro de 2020 com um total de 12 horas como explanado nos Quadros 1 a 4. 
Quadro 1 - Primeira semana da oficina.

\begin{tabular}{|l|}
\hline $1^{a}$ semana: Pesquisa e comunicação científica \\
\hline Período de realização: 01/12/2020 \\
\hline Conteúdo: Conceitos e importância da pesquisa e da comunicação científica e aplicação do pré-questionário. \\
\hline $\begin{array}{l}\text { Propósito: No pré-questionário observar os conhecimentos existentes dos discentes em relação as temáticas da oficina e } \\
\text { comparar o progresso no decorrer da oficina. Trabalhar com os discentes conceitos e objetivos da comunicação científica e } \\
\text { observar como os mesmos fazem suas pesquisas. }\end{array}$ \\
\hline
\end{tabular}

Fonte: Elaboração própria.

Na primeira semana da oficina tivemos a socialização da oficina onde foi discutido o objetivo da oficina e aplicação de pré-questionário com o intuito de se observar a efetividade da pesquisa em relação ao início e o término fazendo um comparativo para observar o conhecimento prévio dos participantes em relação à pesquisa e comunicação científica, currículo Lattes, bases de dados e projeto de pesquisa. Iniciamos a primeira temática da oficina sobre comunicação científica e pesquisa trabalhando conceito, importância e tipos de pesquisa. Foi observado que todos os participantes realizavam suas pesquisas utilizando o buscador do Google sem muita preocupação com a fonte da informação era confiável. Foi proposto aos participantes fazerem uma pesquisa com tema livre. A maioria pesquisou assunto relacionado a coronavírus onde foi mencionado a fonte da informação. As principais fontes de pesquisa foram em sites de notícias. Nesse momento foi explicado a importância de se pesquisar em fontes confiáveis bem como os principais tipos de pesquisa. Na comunicação científica foi trabalhado também as formas dos canais de comunicação e a importância da divulgação científica.

Quadro 2 - Segunda semana da oficina.

\begin{tabular}{|l|}
\hline $2^{\mathbf{a}}$ semana: Elaboração e/ou atualização do currículo Lattes \\
\hline Período de realização: 08/12/2020 \\
\hline Conteúdo: Desenvolver competências para criar o currículo Lattes e atualizar as informações \\
\hline Propósito: Currículo Lattes: histórico, importância, criação e atualização \\
\hline
\end{tabular}

Fonte: Elaboração própria.

No segundo encontro da oficina trabalhamos o currículo Lattes onde o objetivo foi apresentar aos participantes a Plataforma Lattes e instruí-los quanto à realização do cadastro e preenchimento do currículo, além de enfatizar a importância deste para o meio acadêmico. A plataforma Lattes foi uma novidade para todos os participantes. Começamos falando sobre a história do currículo Lattes. Logo em seguida foi mostrada a plataforma Lattes onde se refletiu que o objetivo principal era o participante ter conhecimento e importância de se registrar a vida acadêmica no currículo Lattes através da plataforma. Foi disponibilizado o passo a passo para a criação do currículo na Plataforma Lattes. Como todos os participantes eram discentes do primeiro ano do ensino médio os mesmos ainda não tinham produção acadêmica, mesmo assim foram feitos a criação dos currículos enfatizando a importância de se atualizar sempre que possível.

$\mathrm{Na}$ terceira semana da oficina a temática foram as bases de dados como fontes de comunicação científica onde o objetivo foi despertar o desenvolvimento de competências para o acesso e utilização dessas bases de dados para a produção do conhecimento científico. 
Quadro 3 - Terceira semana da oficina.

\begin{tabular}{|l|}
\hline Terceira semana: Bases de dados como fontes de comunicação científica \\
\hline Período de realização: $15 / 12 / 2020$ \\
\hline $\begin{array}{l}\text { Conteúdo: Desenvolver competências para acessar e utilizar a informação das bases de dados para a produção do } \\
\text { conhecimento científico }\end{array}$ \\
\hline $\begin{array}{l}\text { Propósito: Observar como os discentes realizam suas pesquisas para então fazer uma intervenção utilizando as bases de } \\
\text { dados como fontes de informação confiáveis e disponíveis na internet }\end{array}$ \\
\hline
\end{tabular}

Fonte: Elaboração própria.

Nesse terceiro encontro nenhum dos participantes tinha conhecimento de bases de dados. Resolvemos trabalhar as bases de dados de acesso livre: Portal Brasileiro de Publicação Científica em Acesso Aberto; Portal Domínio Público e Repositório Institucional do IFPB (Instituto Federal da Paraíba). Essa atividade foi realizada de maneira prática onde foi explicado que para realização de trabalhos de cunho acadêmico-científico seria necessário pesquisas de fontes confiáveis como as bases de dados. No Portal Brasileiro de Publicação Científica em Acesso Aberto resolvemos pesquisar temas livres por entender que o gosto para a realização de tais pesquisas devem acontecer com assuntos os quais a pessoa tem curiosidade e afinidade. Os temas mais pesquisados pelos participantes foram saúde mental, Coronavac, coronavírus, vacina. No Portal Domínio Público foi realizada pesquisa com o intuito de entretenimento com obras de Machado de Assis, poesia de Fernando Pessoa e obras de Joaquim Nabuco. No Repositório Institucional foi mostrado as produções intelectuais dos discentes e os periódicos existentes no repositório onde os participantes também puderam fazer pesquisas com temas livres conhecendo assim os trabalhos de conclusão de curso dos discentes do IFPB.

Quadro 4 - Quarta semana da oficina.

\begin{tabular}{|l|}
\hline Quarta semana: Como elaborar projeto de pesquisa de acordo com a ABNT \\
\hline Período de realização: 22/12/2020 \\
\hline Conteúdo: NBR 15287:2011 da ABNT \\
\hline $\begin{array}{l}\text { Propósito: Desenvolver competências em informação com o objetivo de mostrar como é a estrutura e as } \\
\text { etapas para elaboração projeto de pesquisa de acordo com NBR 15287:2011 da ABNT }\end{array}$ \\
\hline
\end{tabular}

Fonte: Elaboração própria.

Na quarta semana da oficina trabalhamos com ABNT NBR 15287:2011 como o objetivo de mostrar a estrutura básica para elaboração do projeto de pesquisa. Foi explicado que a finalidade de uma norma é sempre instruir o autor do trabalho em relação aos elementos obrigatórios, estrutura e formatação do trabalho informando que a norma NBR 15287:2011 serve para especificar como o projeto de pesquisa deve ser elaborado de acordo com a ABNT. Foi mostrado as principais etapas que devem compor um projeto sempre levando em consideração a norma vigente da NBR 15287/2011.

Ao final de cada semana foi aplicado um questionário para fixar o conhecimento de cada participante sendo a última pergunta direcionado a sugestão crítica e/ou elogios. Também foi realizada uma roda de conversa pelo Google Meet ao final de cada encontro com o intuito de se fazer a percepção o quanto foi efetiva ou não a oficina para os participantes. No último dia da oficina foi aplicado um pós-questionário como o objetivo de se comparar os resultados do início da oficina.

\subsection{Rodas de Conversa}

No final de cada oficina foram realizadas rodas de conversa virtual através do Google Meet com o objetivo de motivar uma reflexão e também um compartilhamento de ideias referente as temáticas desenvolvidas fazendo com que houvesse um diálogo e uma interação entre os participantes.

Após o término de cada momento de conversa os participantes elaboraram uma síntese de suas percepções dos temas 
discutidos onde esses textos foram organizados e interpretados seguindo as etapas de análise de conteúdo.

De acordo com Bardin (2011, p.15) a análise de conteúdo "é um conjunto de instrumentos metodológicos cada vez mais sutis em constante aperfeiçoamento que se aplicam a "discurso" (conteúdos e continentes) diversificados". Sendo assim é amplo o seu campo de aplicação podendo ser direcionado por análises tanto por análises qualitativa ou quantitativa. Entendese, portanto, que a análise de conteúdo é viável para se obter mais dos resultados obtidos durante a oficina associando-se a análise quantitativa dos questionários com as análises qualitativas provenientes das rodas de conversa. Três são as análises de conteúdo que segundo Bardin (2011) divide-se em: a) uma pré-análise; b) uma exploração do material examinado; c) o tratamento dos resultados extraídos e interpretação.

Quanto a pré-análise compreende uma leitura geral do material a ser examinado onde se faz necessário fazer uma organização e um direcionamento nas demais partes da análise. A etapa da pré-análise divide-se em 1) A leitura flutuante que consiste em conhecer a fonte que venha a ser analisada; 2) Escolha dos materiais que se baseia na definição do corpus da análise; 3) Formulação das hipóteses e objetivos a partir da primeira leitura dos dados; 4) Elaboração de indicadores cuja finalidade é interpretar o material coletado (Silva \& Fossá, 2015).

Quanto a fase da exploração do material examinado é a parte onde incide no desenvolvimento das operações de codificação devendo ser considerados os recortes dos textos em unidades de registros onde o significado das regras de contagem bem como a classificação e agregação dessas informações em categorias temáticas ou simbólicas. O tratamento desses resultados extraídos e interpretados deve captar os conteúdos manifestos e latentes contidos no material coletado como observação, documentos e entrevistas onde essa análise tida comparativa tem que ser realizada nas diversificadas categorias em cada análise, exibindo os aspectos considerados parecidos e os que foram diferenciados (Silva \& Fossá, 2015). Nessa perspectiva da análise de conteúdo quando falamos em quantitativo seria a frequência que surgem as possíveis características de conteúdo e a análise qualitativa seria a ausência ou presença de uma determinada característica (Bardin, 2011). Iremos trabalhar a análise de conteúdo junto a análise qualitativa levando em consideração que já foi realizado a análise semiquantitativa mediante os questionários. Assim, para se iniciar citam-se os princípios de categorização que são o agrupamento.

Com o corpus coletado se cumpriu as etapas sugeridas pela autora que foram a) uma pré-análise; b) uma exploração do material examinado; c) o tratamento dos resultados extraídos e interpretação.

\section{Resultados e Discussão}

Iremos analisar os resultados obtidos na oficina "O despertar da comunicação científica" e a contribuição da relação entre os conteúdos abordados na construção de uma visão sistêmica e crítica da realidade através da pesquisa como princípio educativo promovendo a reflexão sobre comunicação científica onde a oficina buscou em todos os encontros tentar engajá-los no interesse das temáticas no intuito de fortalecer a compreensão dos assuntos abordados.

Diante da dificuldade de fazer o convite em sala de aula presencialmente devido a pandemia do novo Coronavírus onde os professores tiveram que realizar suas aulas de forma remota consegui fazer o convite em cinco turmas do primeiro ano do ensino médio integrado à educação profissional onde esses professores me forneceu alguns minutos de suas aulas online para que eu pudesse explicar o objetivo da oficina e que a participação seria de forma voluntária e a qualquer momento os alunos poderiam desistir da oficina sem nenhum prejuízo para o aluno e para o pesquisador e que seria preservado o anonimato durante toda a realização da oficina. Foi disponibilizado o link para a inscrição e um contato via WhatsApp e e-mail para eventuais dúvidas da oficina. 


\subsection{Análise do Discurso nas Rodas de Conversa}

A partir do corpus coletado se cumpriu com as etapas que foram uma pré-análise; uma exploração do material examinado; o tratamento dos resultados extraídos e interpretação. Desse modo, foi possível categorizar a partir de um todo as subcategorias: comunicação científica e pesquisa, bases de dados, currículo Lattes, projeto de pesquisa, conforme o Quadro 5.

Quadro 5 - Categoria e subcategoria mediante a oficina.

\begin{tabular}{|l|l|}
\hline \multicolumn{1}{|c|}{ Categoria } & \multicolumn{1}{c|}{ Subcategorias } \\
\hline \multirow{4}{*}{ Oficina Ensino Médio Integrado a Educação Profissional } & Comunicação Científica E Pesquisa \\
\cline { 2 - 2 } & Bases de Dados \\
\cline { 2 - 2 } & Currículo Lattes \\
\cline { 2 - 2 } & Projeto de Pesquisa \\
\hline
\end{tabular}

Fonte: Elaboração própria.

Realizada a identificação da categoria e das subcategorias foram elaborados quatro quadros com suas respectivas subcategorias e unidade de contexto trazendo informações e percepções dos participantes, quanto as suas perspectivas na participação desse estudo. A partir das rodas de conversa sobre comunicação científica e pesquisa foi perguntado como tinha sido para eles a participação e nesse caso podiam escrever qualquer outra informação que representasse a efetividade ou não da oficina. As respostas referentes a essa pergunta estão na unidade de contexto no Quadro 6.

Quadro 6 - Unidade de contexto comunicação científica e pesquisa.

\begin{tabular}{|c|c|}
\hline Subcategoria & Unidade de Contexto \\
\hline \multirow{13}{*}{$\begin{array}{l}\text { Comunicação científica } \\
\text { e pesquisa }\end{array}$} & $\begin{array}{l}\text { D1 "Eu entendi o quanto é importante a comunicação científica e também desenvolvermos pesquisas sobre } \\
\text { determinado tema". }\end{array}$ \\
\hline & D2 "Eu quero ser pesquisador e contribuir para a população. Gostei de como foi exposto a temática". \\
\hline & $\begin{array}{l}\text { D3 "A divulgação científica é uma forma de os pesquisadores iniciantes começarem o interesse pela } \\
\text { pesquisa". }\end{array}$ \\
\hline & D4 “Foi bem interessante e irá me ajudar nas próximas pesquisas que eu desenvolver”. \\
\hline & $\begin{array}{l}\text { D5 "Consegui obter bastante conhecimento, principalmente sobre os tipos de pesquisa. Com certeza irá me } \\
\text { ajudar no futuro, pois obtive mais conhecimento". }\end{array}$ \\
\hline & $\begin{array}{l}\text { D6 "Foi muito útil para minha vida acadêmica, pois eu aprendi a importância de se registrar a pesquisa para o } \\
\text { conhecimento das futuras gerações". }\end{array}$ \\
\hline & $\begin{array}{l}\text { D7 "Não conhecia muito de comunicação científica e pesquisa, porém através da oficina descobri e aprendi } \\
\text { muito sobre". }\end{array}$ \\
\hline & D8 “Foi bem interessante. Eu não conhecia os tipos de pesquisa e agora eu sei e vai me ajudar." \\
\hline & D9 "Toda pessoa que quiser ser pesquisador deveria assistir essa oficina”. \\
\hline & D10 "Muito bom saber a importância da comunicação científica e da pesquisa no mundo acadêmico". \\
\hline & D11 “Me ajudou muito tudo que foi ensinado. Vou usar durante toda minha vida acadêmica”. \\
\hline & D12 “Comunicação científica são fontes de informações verdadeiras”. \\
\hline & D13 “Agora eu vou conseguir saber se determinada informação é verdadeira”. \\
\hline
\end{tabular}

Fonte: Elaboração própria.

A partir do recorte do corpus foram feitos alguns agrupamentos de registros similares ou com destaque em relação ao conteúdo ministrado. Assim sendo os trechos foram: D1 "o quanto é importante a comunicação científica", D5 "irá me ajudar no futuro", D6 "muito útil para minha vida acadêmica", D8 "foi bem interessante", D11 "me ajudou muito" mostra a relevância da temática para os discentes até por se tratar de um tema o qual não tinha sido estudado por eles, despertando assim, o interesse pelo tema. O segundo agrupamento D7 "não conhecia muito de comunicação científica", D8 "eu não conhecia os tipos de pesquisa" reforça que os discentes não tinham, até então, conhecimento sobre comunicação científica e pesquisa sendo para eles o primeiro contato sobre a temática através da oficina. O terceiro agrupamento D2 "eu quero ser 
pesquisador", D4 "irá me ajudar nas próximas pesquisas", D5 "com certeza irá me ajudar no futuro pois obtive mais conhecimento" mostra o interesse inicial dos discentes em trabalhar com pesquisas.

Na roda de conversa sobre bases de dados o pesquisador perguntou o que achou da oficina, se achou fácil, difícil, se ajudará em suas pesquisas, além de qualquer outra informação que tivessem o desejo de compartilhar. O Quadro 7 apresenta o recorte da unidade de contexto mediante subcategoria bases de dados.

Quadro 7 - Unidade de contexto bases de dados.

\begin{tabular}{|c|c|}
\hline Subcategoria & Unidade de Contexto \\
\hline \multirow{7}{*}{ Bases de dados } & $\begin{array}{l}\text { D1 "Através da oficina consegui entender o funcionamento de diversas bases de dados além de aprender a fazer } \\
\text { pesquisa de forma correta". }\end{array}$ \\
\hline & D2 "Ao longo da oficina aprendi que se deve pesquisar em fontes confiáveis como as bases de dados". \\
\hline & D3 “As bases de dados nos ajudam a pesquisar de forma mais confiável”. \\
\hline & $\begin{array}{l}\text { D4 "A oficina nos ajudou a identificar diversas bases de dados que não sabíamos que tinha e poderá realizar } \\
\text { pesquisas de maneira correta e com fonte confiável". }\end{array}$ \\
\hline & D5 “Todo aluno deveria saber da existência das bases de dados. É excelente”. \\
\hline & D6 "As bases de dados vão me ajudar muito a realizar minhas atividades". \\
\hline & D7 “. É uma excelente fonte de pesquisa”. \\
\hline
\end{tabular}

Fonte: Elaboração própria.

Do agrupamento D1 "fazer pesquisa de forma correta", D2 "pesquisar em fontes confiáveis", D4 "realizar pesquisas de maneira correta" demonstra que ficou entendido a importância e o objetivo das bases de dados como fontes de comunicação científica confiável facilitando suas futuras pesquisas Os agrupamentos D5 "é excelente", D6 "vão me ajudar muito", D7 "é uma excelente fonte de pesquisa" esses recortes demonstram a satisfação dos participantes nesse módulo e a relevância das informações que adquiriram onde não precisam estar pesquisando em vários sites visto que as bases de dados reúnem é um só ambiente revistas e artigos facilitando a vida dos pesquisadores.

$\mathrm{Na}$ roda de conversa sobre currículo Lattes o pesquisador perguntou como foi a oficina, se achou, fácil, difícil, importante ou qualquer outra informação que desejasse compartilhar. O quadro 8, expõe o recorte da unidade de contexto mediante a subcategoria currículo Lattes.

Quadro 8 - Unidade de contexto currículo Lattes.

\begin{tabular}{|l|l|}
\hline Subcategoria & \multicolumn{1}{|c|}{ Unidade de Contexto } \\
\hline \multirow{4}{*}{$\begin{array}{c}\text { Lurrículo } \\
\text { Lattes }\end{array}$} & D1 "Ajudou bastante, gostei muito de ter conhecido o currículo Lattes". \\
\cline { 2 - 3 } & D2 "Foi de suma importância conhecer o currículo Lattes." \\
\cline { 2 - 3 } & D3 "Foi muito intuitivo. Não conhecia o currículo Lattes e agora conheço". \\
\cline { 2 - 3 } & D4 "Eu não tinha ideia como funcionava. Com a prática, aprendi como funcionava". \\
\cline { 2 - 3 } & D7 "Au não conhecia e foi muito bom conhecer". \\
\cline { 2 - 3 } & D8 "Me ajudou a construir meu currículo". \\
\cline { 2 - 3 } & D9 "Ajudou e vou divulgar para outras pessoas". \\
\cline { 2 - 3 } & D10 "Muito agradecido por ter nos apresentado o currículo Lattes". \\
\cline { 2 - 3 } & D11 "Para mim foi ótima, não conhecia e irei usar bastante". \\
\hline
\end{tabular}

Fonte: Elaboração própria. 
Analisando o recorte do corpus agrupa-se da seguinte forma: D1 “ajudou bastante”, D5 "muito bom”, D11 "foi ótima" o agrupamento exprime o que foi para os participantes quanto as participações mostrando que gostaram de estar vivenciando esse momento. O segundo agrupamento D3 "Não conhecia", D4 "não tinha ideia", D6 "não conhecia", D11 "não conhecia" legitima a importância da temática até mesmo de forma inédita pois em sua grande maioria não conheciam essa ferramenta importante para o registo de informações científicas e acadêmicas na oficina sobre o uso da plataforma do currículo Lattes colaborando no momento da prática quanto a construção de cada currículo na plataforma Lattes. O D3 "foi muito intuitivo" mostra que foi compreendido essa vivência em que foi abordado a teoria e a prática do currículo na plataforma Lattes.

$\mathrm{Na}$ roda de conversa sobre a estrutura do projeto de pesquisa o pesquisador perguntou como foi a oficina se achou fácil, difícil, se ajudaria em seu processo acadêmico ou qualquer outra informação que desejasse compartilhar. No quadro 9, é feito um recorte da unidade de contexto mediante subcategoria referente a estrutura projeto de pesquisa.

Quadro 9 - Unidade de contexto estrutura do projeto de pesquisa

\begin{tabular}{|l|l|}
\hline Subcategoria & \multicolumn{1}{c|}{ Unidade De Contexto } \\
\hline \multirow{4}{*}{$\begin{array}{c}\text { Estrutura do projeto } \\
\text { de pesquisa }\end{array}$} & D1 "A dinâmica foi muito boa, pois eu não sabia que existia uma norma para fazer projeto de pesquisa". \\
\cline { 2 - 2 } & D2 "Tive um pouco de dificuldade nesse primeiro contato". \\
\cline { 2 - 2 } & D3 "Ajudou muito e se faz necessário termos esse conhecimento se quisermos fazer projeto". \\
\cline { 2 - 2 } & D4 "Contribuiu bastante". \\
\cline { 2 - 2 } & D5 "Foi um pouco dificil por se tratar de muitos detalhes". \\
\cline { 2 - 3 } & D6 "Apesar de muitos detalhes eu gostei de participar". \\
\cline { 2 - 3 } & $\begin{array}{l}\text { D7 "Ainda não tinha uma experiência com norma da ABNT, então esse encontro me ajudou a tentar construir } \\
\text { meu projeto no futuro". }\end{array}$ \\
\hline
\end{tabular}

Fonte: Elaboração própria.

A partir do recorte e agrupamento constatou-se que: D2 “Tive um pouco de dificuldade”, D5 “um pouco difícil”, D6 "muitos detalhes" mostram que a norma da ABNT se mostrou um pouco cansativa para esses participantes. Foi lembrado que norma serve para ser consultada e não decorada. Já o agrupamento D1 "a dinâmica foi muito boa", D3 “ajudou muito", D4 "contribuiu bastante" mostra a relevância dessa temática que foi colocada na oficina.

\subsection{Análise dos Questionários}

$\mathrm{Na}$ aplicação dos questionários 21 discentes responderam o pré-questionário (início da oficina) e o pós-questionário (término da oficina) foi respondido por 15 discentes. Com isso foram seis a menos correspondendo a 28,58\% de desistentes entre o início e o término da oficina. O objetivo da aplicação dos questionários foi saber se tivemos ou não alguma evolução em relação aos conteúdos abordados durante a oficina. Nos Gráficos 1 a 5 são mostrados esses resultados conforme os questionamentos abordados. 
Gráfico 1 - Canais formais de comunicação

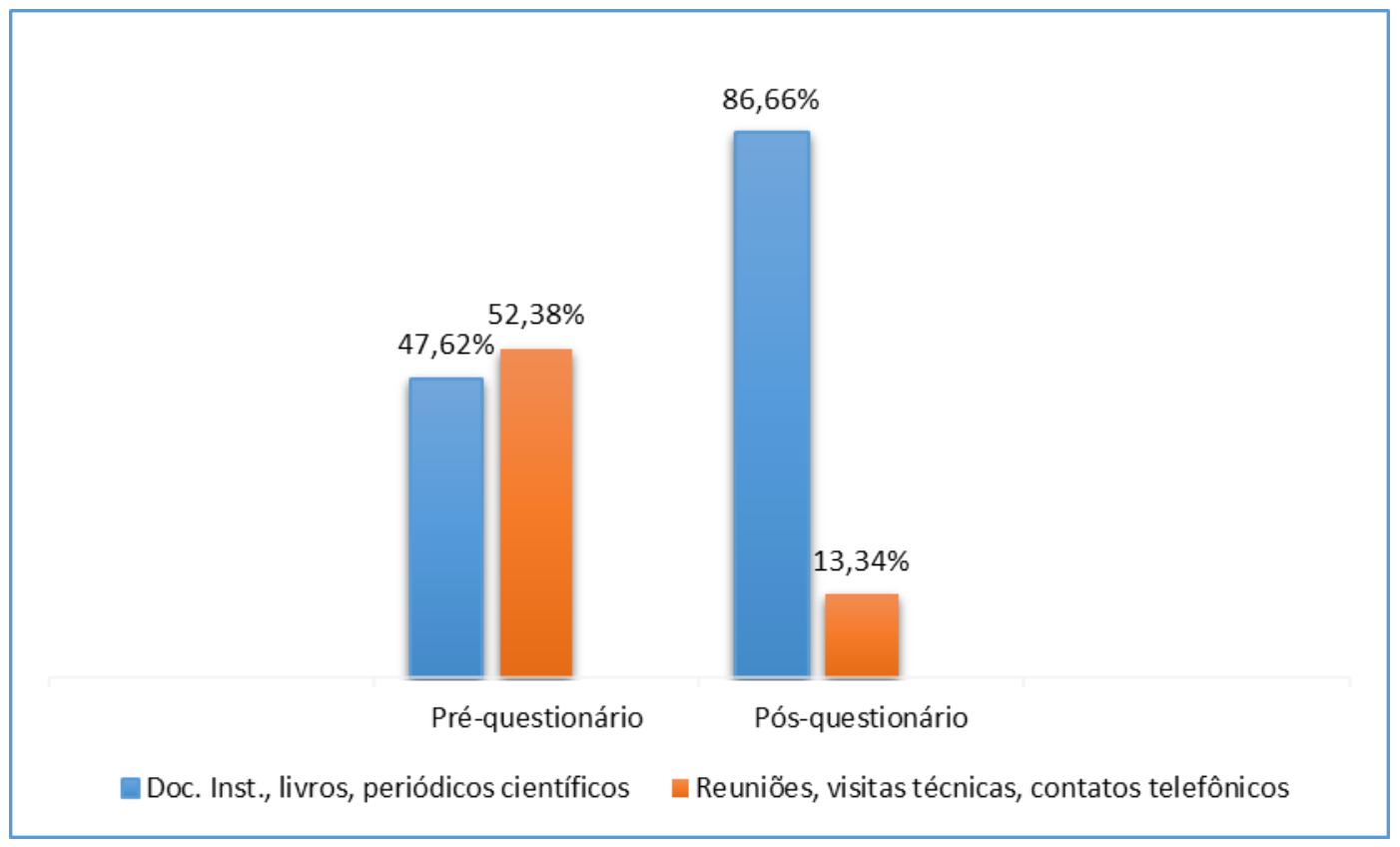

Fonte: Elaboração própria.

No Gráfico 1, temos a discussão do item “os canais formais de comunicação científica são aqueles que veiculam informações já estabelecidas ou comprovadas através de estudos. São exemplos de canais formais de comunicação: a) documentos institucionais, livros, periódicos científicos; b) reuniões, visitas técnicas, contatos telefônicos". Com base no préquestionário $47,62 \%$ dos discentes responderam a assertiva correta que é documentos institucionais, livros, periódicos científicos. Já no pós-questionário o percentual foi de $86,66 \%$ que responderam documentos institucionais, livros, periódicos científicos. Dessa forma, percebe-se que houve uma evolução de 39,04\% entre o pré-questionário (antes da oficina) e pósquestionário (depois da oficina). Essa evolução do entendimento sobre os canais formais de comunicação é de suma importância no desenvolvimento do conhecimento de uma produção científica como a elaboração de um artigo para a publicação em uma revista acadêmico-científico e um trabalho de conclusão de curso para ser depositado em um repositório institucional, por exemplo. 
Gráfico 2 - Canais informais de comunicação.

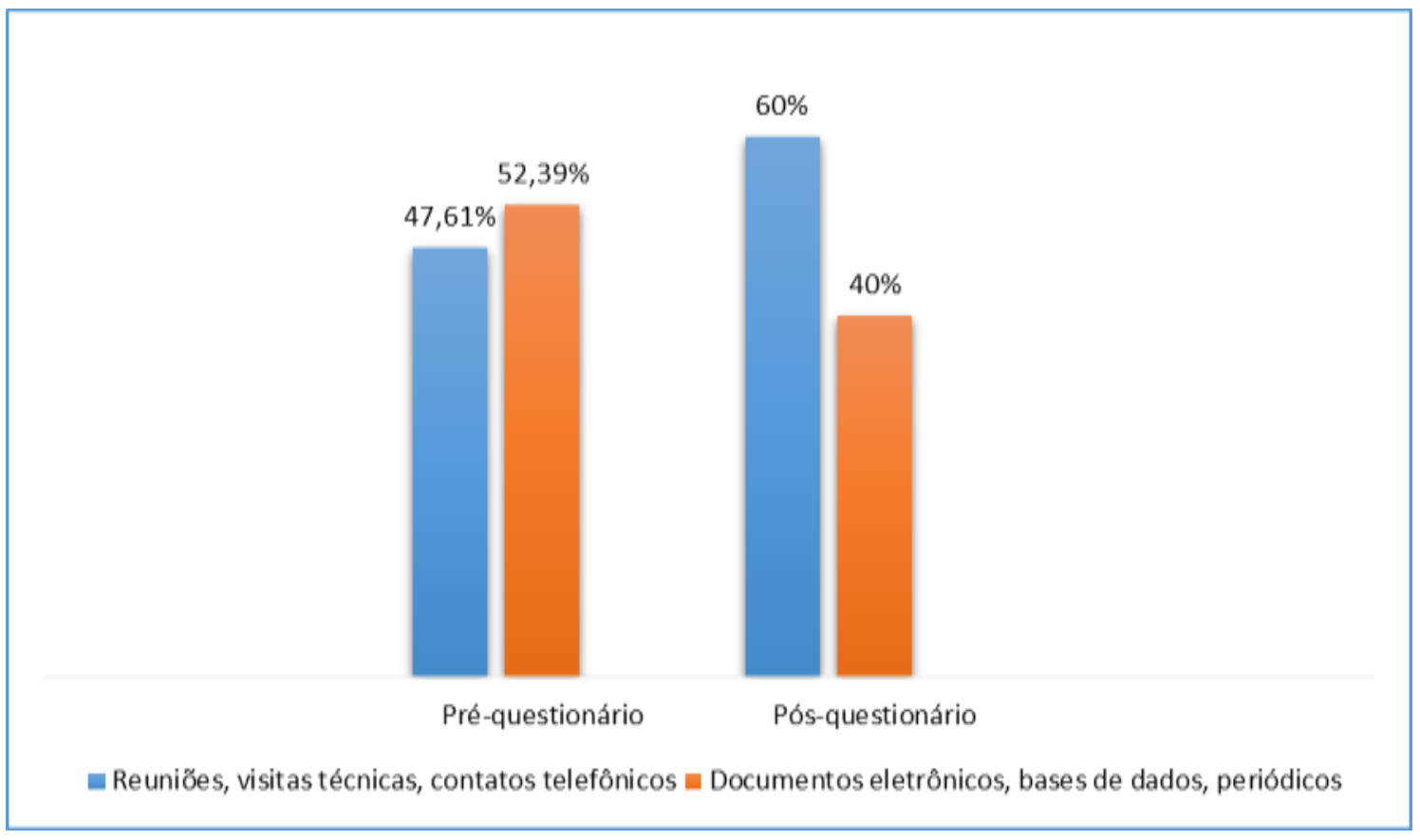

Fonte: Elaboração própria.

No Gráfico 2, temos a discussão do item "os canais informais de comunicação são aqueles caracterizados por contatos realizados entre os sujeitos emissores e receptores de informação, configurando-se em contatos interpessoais. São exemplos de canais informais: a) reuniões, visitas técnicas, contatos telefônicos; b) documentos eletrônicos, bases de dados, periódicos". No pré-questionário 47,61\% responderam a assertiva correta: reuniões, visitas técnicas, contatos telefônicos. Após a realização da oficina esse percentual de assertiva correta foi de $60 \%$. No comparativo entre o pré-questionário e o pós-questionário observamos um crescimento de $12,39 \%$ e, portanto, uma evolução no entendimento do que seria comunicação informal referente a comunicação científica. 
Gráfico 3 - Bases de dados.

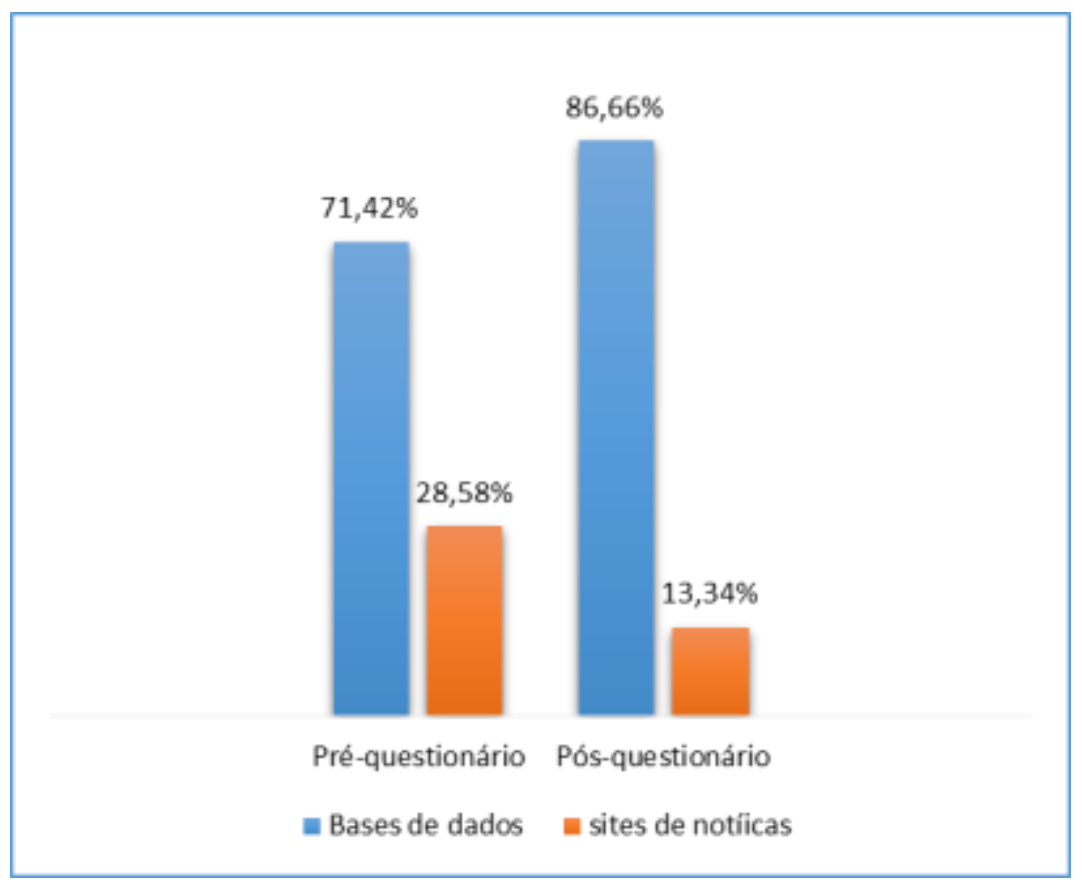

Fonte: Elaboração própria.

No Gráfico 3, temos a discussão do item "disponibilizam centenas de revistas, artigos, teses, dissertações com o objetivo de disseminar a comunicação científica são: a) as bases de dados; b) sites de notícias". Nesse quesito podemos perceber que antes da realização da oficina, $71,42 \%$ acertaram a assertiva que são as bases de dados enquanto que $28,58 \%$ afirmaram ser os sites de notícias. Após a realização da oficina o entendimento do que seriam bases dados aumentou para $86,66 \%$, ou seja, tivemos um aumento de $15,24 \%$ o que reflete que houve um aumento no entendimento do conceito referente ao termo bases de dados voltados para a comunicação científica e sua importância para os pesquisadores visto que as bases de dados são fontes de informação científica onde estão registradas produções de diversas áreas do conhecimento. 
Research, Society and Development, v. 10, n. 16, e507101622968, 2021

(CC BY 4.0) | ISSN 2525-3409 | DOI: http://dx.doi.org/10.33448/rsd-v10i16.22968

Gráfico 4 - Currículo Lattes.

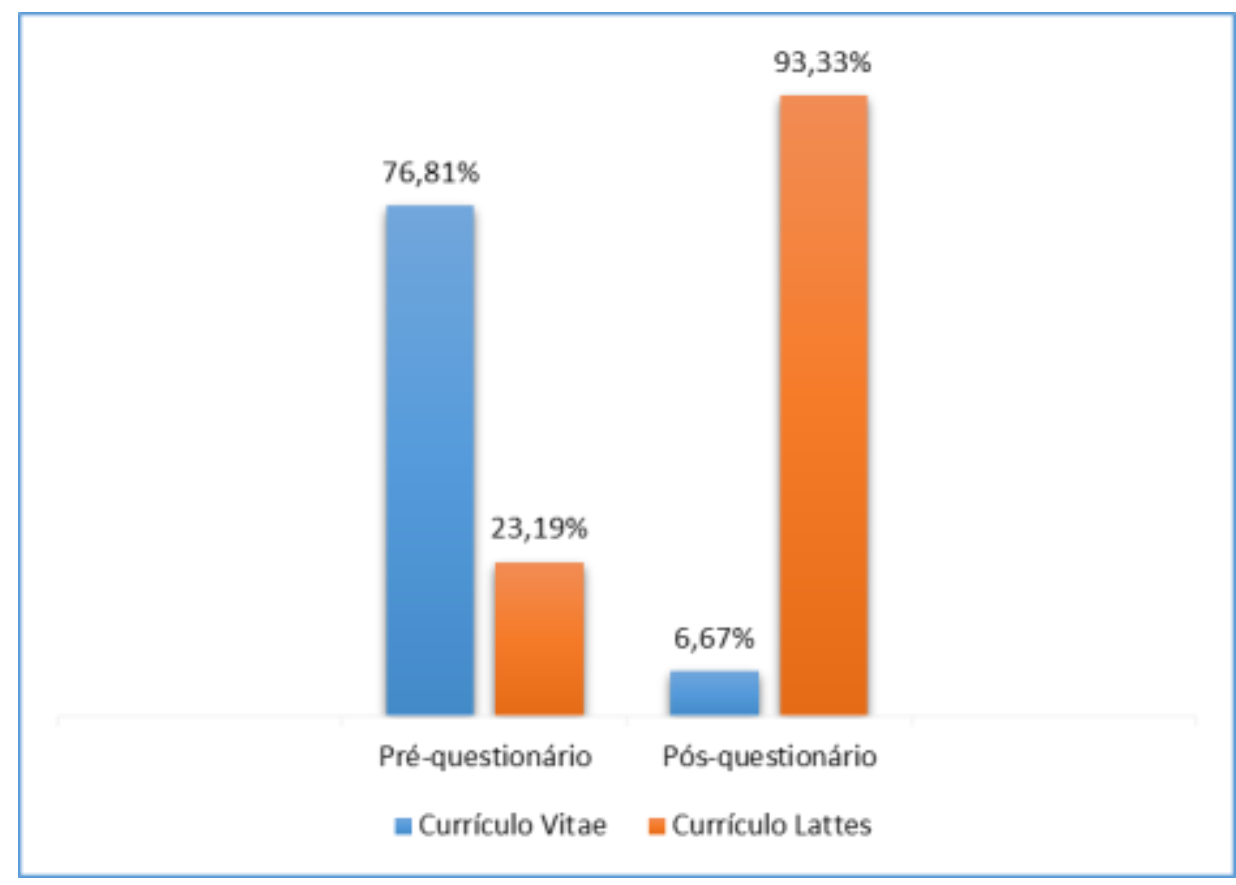

Fonte: Elaboração própria.

No Gráfico 4, temos a discussão do item “tornou um padrão nacional no registro do percurso acadêmico de estudantes e pesquisadores do Brasil. Atualmente é dotado pela maioria das instituições de fomento, universidades e institutos de pesquisa do país. Esse conceito é do: a) currículo Lattes; b) currículo Vitae". Antes da realização da oficina quando aplicamos o préquestionário tivemos apenas um percentual de 23,19\% afirmando que o conceito acima é referente a assertiva correta que é o currículo Lattes. Já no pós-questionário tivemos um percentual de 93,33\% afirmando que a assertiva correta é o currículo Lattes o que nos leva a compreender que o aluno do ensino médio integrado à educação profissional entra nessa fase sem o conhecimento do conceito e importância do currículo Lattes para sua formação acadêmica. 
Gráfico 5 - Produção científica.

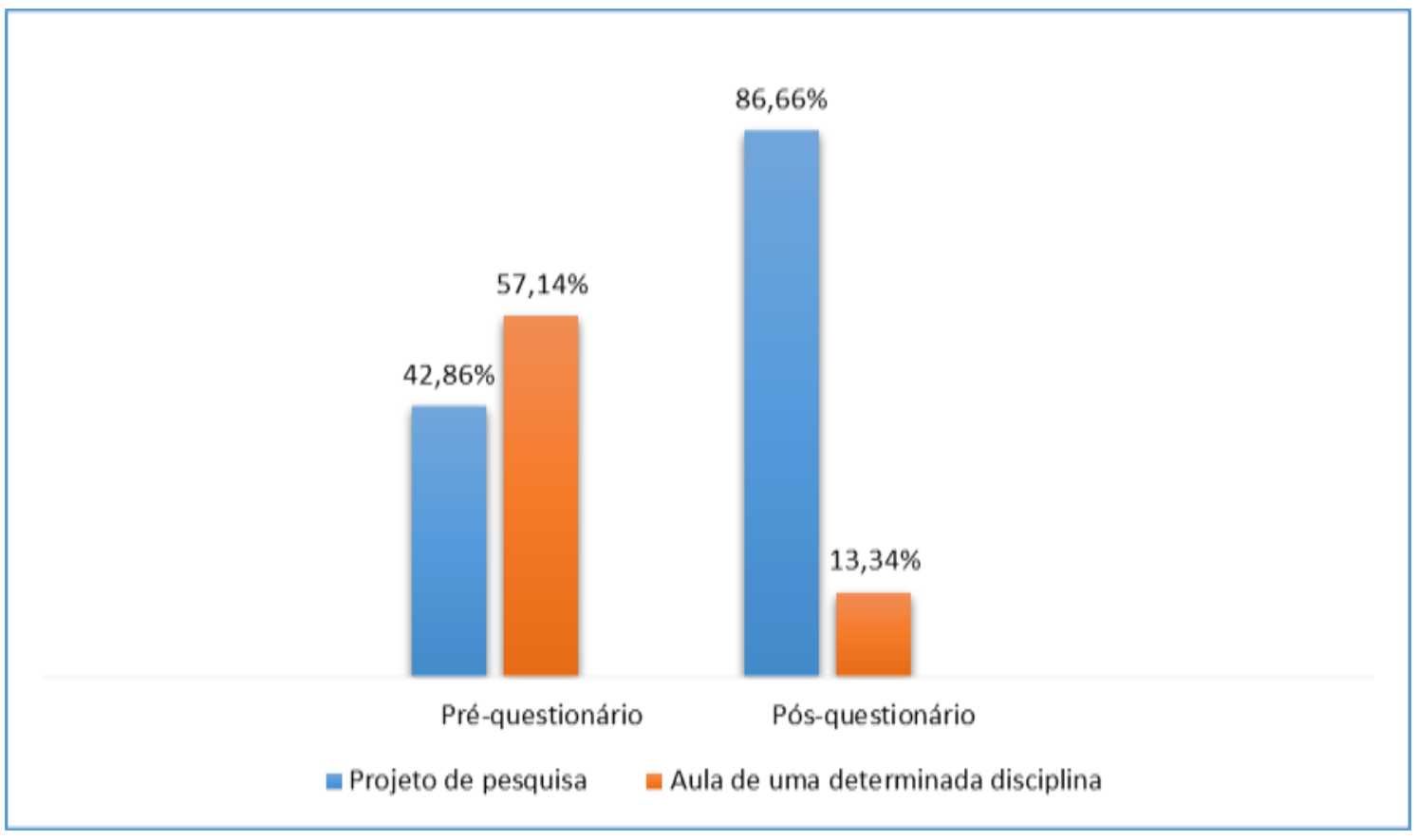

Fonte: Elaboração própria.

No Gráfico 5 temos a discussão do item "consiste numa importante etapa da produção científica por parte do aluno. É nele que o estudante esboça, delimita e expõe ao professor/orientador seu objeto de estudo, explicitando o tipo de abordagem que pretende dar ao assunto sobre o qual discorrerá. Esse conceito define: a) Projeto de pesquisa; b) Aula de uma determinada disciplina”. Nessa questão tivemos no pré-questionário um percentual de $57,14 \%$ respondendo a afirmativa correta que o conceito se refere a projeto de pesquisa. Já no pós-questionário esse percentual de assertiva correta foi de 86,66\% havendo nesse caso uma evolução sobre o entendimento dessa temática apesar de muitos desses alunos entrarem no ensino médio integrado à educação profissional sem nunca terem participado de um projeto de pesquisa.

Com base nos resultados extraídos dos questionários foi possível observar que houve uma evolução quando comparado a aplicação do pré-questionário com o pós-questionário. Não obstante, os dados gerais dos questionários aliados as rodas de conversas mostram que os discentes tiveram acesso a informações relevantes que ainda não tinham tido acesso a essas temáticas. Iremos analisar os resultados obtidos na oficina "O despertar da comunicação científica" e a contribuição da relação entre os conteúdos abordados na construção de uma visão sistêmica e crítica da realidade através da pesquisa como princípio educativo promovendo a reflexão sobre comunicação científica onde a oficina buscou em todos os encontros tentar engajá-los no interesse das temáticas no intuito de fortalecer a compreensão dos assuntos abordados.

Diante da dificuldade de fazer o convite em sala de aula presencialmente devido a pandemia do novo Coronavírus onde os professores tiveram que realizar suas aulas de forma remota consegui fazer o convite em cinco turmas do primeiro ano do ensino médio integrado à educação profissional onde esses professores me forneceu alguns minutos de suas aulas online para que eu pudesse explicar o objetivo da oficina e que a participação seria de forma voluntária e a qualquer momento os alunos poderiam desistir da oficina sem nenhum prejuízo para o aluno e para o pesquisador e que seria preservado o anonimato durante toda a realização da oficina. Foi disponibilizado o link para a inscrição e um contato via WhatsApp e e-mail para eventuais dúvidas da oficina. 


\section{Considerações Finais}

Pesquisas baseadas em experiências reais sobre o uso da comunicação científica em ambientes escolares vem sendo debatida e defendida nos últimos anos, porém ainda não existe um material abrangente envolvendo essa temática e com isso elaboramos um estudo com o objetivo de oferecer uma oficina sobre comunicação científica voltado aos alunos do primeiro ano do ensino médio integrado à educação profissional para avaliar o desenvolvimento desses alunos em relação ao domínio e a apropriação de conceitos relacionados a temática proposta.

Nossa análise mostrou características positivas quanto ao uso de métodos utilizados para o aprendizado e o conhecimento desses alunos. Embora os participantes tivessem pouco ou nenhum conhecimento prévio sobre comunicação científica e sua importância para a comunidade, aos poucos alguns deles começaram a fazer o domínio das ferramentas necessárias para ter acesso a comunicação científica empregando novas formas de linguagem e fazendo com que houvesse uma intensificação nesse processo de aprendizagem dos temas disponibilizados na oficina.

As opiniões expressas pelo grupo em relação a oficina reforçam a importância desse tipo de atividade, pois levam em consideração que as tarefas que foram desempenhadas puderam contribuir para o desenvolvimento de habilidades necessárias à formação acadêmica, ao aperfeiçoamento da escrita científica e ao entendimento referente ao processo de desenvolvimento e construção do conhecimento científico.

O nosso estudo apresenta apenas um pequeno exemplo de como a comunicação científica pode ser aplicada no ambiente escolar e também serve para ilustrar alguns benefícios como a estreita relação entre linguagem e pensamento. Assim quando se solicita ao aluno que escreva algo o impõe a ele a tarefa de pensar sobre este assunto, pois o ato de pensar envolve muito mais do que simplesmente expor ideias armazenadas na cabeça. Faz-se necessário que as deias sejam repensadas e organizadas para finalmente serem expostas.

Considerando os esforços aplicados na resolução do problema proposto neste estudo acreditamos que a proposta teve uma boa receptividade e atingiu o objetivo de estimular o interesse pela comunicação científica como um todo, além de proporcionar o desenvolvimento de outras habilidades, de caráter formativo, como a linguagem científica (mesmo que reduzida), o trabalho em grupo e o senso crítico.

\section{Referências}

Baldino, R. R. (2021). 13 Pesquisa-Ação Para Formação De Professores: Leitura Sintomal De Relatórios. Pesquisa em educação matemática: concepções e perspectivas.

Barbier, R. A. (2007). Pesquisa-ação. Liber.

Barbosa, E. C. B. F., \& Moreira, H. B. C. (2020). A relevância da Biblioteca Multinível diante da efetivação dos direitos educacionais dos usuários com deficiência visual e motora. Research, Society and Development, 9(1), e19911529-e19911529.

Bardin, L. (2011). Análise de conteúdo. Almedina.

Cunha, M. B. D. (1997). Biblioteca digital: bibliografia internacional anotada. Ciência da Informação, 26.

Demo, P. (2003). Educar pela pesquisa. (7a ed.) Autores Associados.

Francisco, A. C., \& Fernandes-Sobrinho, M. (2020). Biblioteca e Educação Profissional e Tecnológica: lacunas e potencialidades frente a aspectos formativos críticos. Research, Society and Development, 9(9), e392996999-e392996999.

Holanda, R. (2000). Escola, leitura e produção de textos. Artes Médicas.

Júnior, J. A. L., Fernandes, A. J., \& Formiga, N. S. (2021). Escala sobre atitudes da aprendizagem colaborativa associada às tecnologias da informação e comunicação: Validade e diferenças nas IES públicas e privadas na cidade de Natal-RN. Research, Society and Development, 10(3), e51710313710e51710313710.

Magalhães, S. R., Rodrigues, L. M., \& Pereira, C. A. (2021). Metodologias Ativas Que Empregam Tecnologias Digitais De Informação E Comunicação (Tdic) No Ensino Médio Integrado. Revista Prática Docente, 6(3), e083-e083. 
Research, Society and Development, v. 10, n. 16, e507101622968, 2021

(CC BY 4.0) | ISSN 2525-3409 | DOI: http://dx.doi.org/10.33448/rsd-v10i16.22968

Morigi, V. J., \& Pavan, C. (2004). Tecnologias de informação e comunicação: novas sociabilidades nas bibliotecas universitárias. Ciência da Informação, 33, $117-125$.

Ninsembaum, H. (2001). Gestão do conhecimento. In: Boog, G. (2001) Manual de treinamento e desenvolvimento: um guia de operações. Makron Books.

Olinto, G. (2010). Bibliotecas públicas e uso das tecnologias de informação e comunicação para o desenvolvimento social.

Ribeiro, L. V. M., \& Chahini, T. H. C. (2021). Tecnologias digitais de informação e comunicação em biblioteca universitária. Brazilian Journal of Development, 7(4), 39331-39346.

Saraiva, C. M., \& dos Anjos, Á. M. G. (2020). A Pesquisa-Ação no ensino superior: um caminho de (trans) formação individual e social. Administração: Ensino e Pesquisa, 21(3), 282-315.

Silva, A. H. \& Fossá. M. I. T. (2015). Análise de conteúdo: exemplo de aplicação da técnica para análise de dados qualitativos. Qualitas Revista Eletrônica. $16(2), 01-14$.

Thiollent, M. (2007). Metodologia da pesquisa-ação. (15a ed.) Cortez. 